BMJ Open Diabetes

Research \& Care

\title{
Cardiovascular risk factors from diagnosis in children with type 1 diabetes mellitus: a longitudinal cohort study
}

\author{
Stephanie Jones (D) , ${ }^{1}$ Amal R Khanolkar, ${ }^{1,2}$ Evelien Gevers, ${ }^{3,4}$ \\ Terence Stephenson, ${ }^{1}$ Rakesh Amin ${ }^{1}$
}

\begin{abstract}
To cite: Jones S, Khanolkar AR, Gevers E, et al. Cardiovascular risk factors from diagnosis in children with type 1 diabetes mellitus: a longitudinal cohort study. BMJ Open Diab Res Care 2019;7:e000625. doi:10.1136/ bmjdrc-2018-000625
\end{abstract}

This work has been presented at the following meetings: Royal College of Paediatrics and Child Health Conference, March 2018; 1st World Congress on Migration, Ethnicity, Race and Health. May 2018 ; ISPAD 44th Annual Conference, October 2018 (poster presentation).

Received 17 October 2018 Revised 4 July 2019 Accepted 2 August 2019

Check for updates

C) Author(s) (or their employer(s)) 2019. Re-use permitted under CC BY-NC. No commercial re-use. See rights and permissions. Published by BMJ.

${ }^{1}$ GOS Institute of Child Health, UCL, London, UK

${ }^{2}$ Institute of Environmental Medicine, Karolinska Institutet, Stockholm, Sweden

${ }^{3}$ Department of Paediatric

Endocrinology, Barts Health NHS Trust, Royal London Children's Hospital, London, UK ${ }^{4}$ Centre for Endocrinology, Queen Mary University of London, London, UK

Correspondence to Dr Amal R Khanolkar; a.khanolkar@ucl.ac.uk

\section{ABSTRACT}

Background For childhood onset type 1 diabetes (T1D), the pathogenesis of atherosclerosis is greatly accelerated and results in early cardiovascular disease (CVD) and increased mortality. However, cardioprotective interventions in this age group are not routinely undertaken.

Aims To document prevalence of cardiovascular risk factors from diagnosis of childhood T1D and their relationship with disease duration and ethnicity. Methods Routinely collected clinical records for 565 children with $\mathrm{T1D}$ were retrospectively analyzed. Data were collected from diagnosis and at routine check-ups at pediatric diabetes clinics across Barts Health National Health Service Trust. Age at diagnosis was 8.5 years (0.919.4). Mean follow-up 4.3 years (0-10.8). $48 \%$ were boys and $60 \%$ were non-white. Linear longitudinal mixed effects models were used to evaluate relationships between risk factors and diabetes duration.

Results CVD risk factors were present at first screening; $33.8 \%$ of children were overweight or obese, $20.5 \%$ were hypertensive (elevated diastolic blood pressure (BP)) and total cholesterol, low-density lipoprotein-cholesterol and high-density lipoprotein-cholesterol were abnormal in $63.5 \%, 34.2 \%$ and $22.0 \%$, respectively. Significant associations between diabetes duration and annual increases of body mass index $\left(0.6 \mathrm{~kg} / \mathrm{m}^{2}\right)$, BP $(0.1 \mathrm{SD}$ score) and lipids (0.02-0.06 mmol/L) were noted. Annual increases were significantly higher in black children for BP and Bangladeshi children for lipids. Bangladeshi children also had greatest baseline levels.

Conclusions CVD risk factors are present in up to $60 \%$ of children at diagnosis of T1D and increase in prevalence during the early years of the disease. Commencing screening in younger children and prioritizing appropriate advice and attention to ethnic variation when calculating risk should be considered.

\section{INTRODUCTION}

Life expectancy for children and young people (CYP) with type 1 diabetes (T1D) is reduced by up to 13 years compared with the general population, with cardiovascular disease (CVD) the leading cause of death in adulthood. ${ }^{1-3}$ The landmark Adolescent Type

\section{Significance of this study}

What is already known about this subject?

- Accelerated atherosclerosis in children diagnosed with type 1 diabetes results in earlier morbidity and mortality from cardiovascular disease (CVD).

What are the new findings?

- Prevalence of modifiable CVD risk factors are high at diagnosis in all age groups. Rising levels of risk factors are associated with increasing diabetes duration but with significant ethnic variation.

How might these results change the focus of research or clinical practice?

- A review of current UK screening recommendations to include younger children may enable earlier identification and management of CVD risk factors. Clinicians may consider more aggressive monitoring and management of risk factors in high-risk ethnic groups.

1 Diabetes Cardio-Renal Intervention Trial (AdDIT) showed that aortic intima-media thickness, which predicts CVD morbidity and mortality, is increased. ${ }^{4}$ Endothelial dysfunction, a commonly used surrogate marker for evolving atherosclerosis, has been noted in CYP with T1D from 5years postdiagnosis. ${ }^{56}$ Furthermore, the 2017 England and Wales National Paediatric Diabetes Audit, one of the largest datasets of its kind, has found high prevalence of CVD risk factors in CYP with T1D. ${ }^{7}$ Excess deaths in T1D attributed to CVD begin to emerge in young adults under 25 years. ${ }^{8}$ This indicates that the pathogenesis of CVD in T1D is accelerated. However, no studies have documented the prevalence of CVD risk factors from diagnosis of T1D. This would be important as it may help inform the timing of cardioprotective intervention, which currently is at low rates in this age group. ${ }^{9}$ 
Adult incidence of CVD varies between different ethnicities, with minority groups having higher reported rates of both risk factors and events even after adjusting for disparities in healthcare, suggesting inherent factors and different response to treatment may be important. ${ }^{10-14}$ South Asian groups living in the UK are at particular risk, with the highest CVD mortality rates that also occurs at a younger age and lower levels of dyslipidemia and obesity, ${ }^{15-17}$ leading some to conclude this group has an increased atherogenic burden than other ethnicities. ${ }^{18}$ The American SEARCH for Diabetes in Youth group found rising lipid parameters with increasing disease duration, but there was no comment on ethnic variation, and as yet the relationship with other risk factors in CYP remains unexplored. ${ }^{19}$

We investigated the prevalence of CVD risk factors at diagnosis of T1D and their relationship with disease duration in a multiethnic group of CYP attending specialist pediatric diabetes care clinics.

\section{METHODS}

\section{Participants}

We studied all CYP diagnosed with T1D attending routine health check-ups at three East London pediatric diabetes clinics across Barts Health National Health Service (NHS) Trust between 2005 and 2015. Patients received care in line with national recommendations, ${ }^{20}$ with clinical measures and sociodemographic data collected at diagnosis and during subsequent routine follow-up visits. CYP attended from diagnosis until transition to adult services (generally between 16 years and 18 years). The majority lived within surrounding local authorities, where there are high levels of ethnic diversity and socioeconomic deprivation. ${ }^{21} 22$ Assignment to T1D was made on clinical basis as antibodies were not documented for all children. Data analysis was retrospective and restricted to children diagnosed during the study period (2005-2010) where data for age, gender, ethnicity and glycated hemoglobin (HbAlc) was available, $\mathrm{n}=565$ (figure 1). As the date of diagnosis was not the same for all children, the maximal length of follow up for each individual varied depending on when they were diagnosed during the study period. Further details for this cohort and the care delivered by the diabetes team have previously been described. ${ }^{23}$

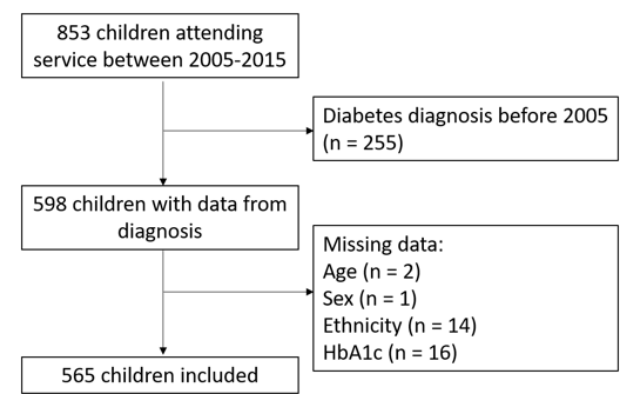

Figure 1 Flow chart of children in the database with exclusion criteria. HbA1c, glycated hemoglobin.
Main outcomes

\section{Body mass index (BMI)}

Anthropometry was measured in accordance with national guidance. ${ }^{24} 25$ BMI was calculated using the formula $\frac{w e i g h t(k g)}{h e i g h t \times h e i g h t(m)}$. The first 3 months after diagnosis, where there is normalization to premorbid weight, was excluded..$^{26}$ The distribution of BMI varies with age and $\operatorname{sex}^{27}$; therefore, it is usual to express this as a standard deviation score (SDS) and compare against a growth reference. The most commonly used in the UK is the British 1990 Growth Reference charts (UK90), which define overweight as between the 85th and 95th percentile (SDS +1.036 to +1.645 ) and obese $\geq 95$ th percentile $(\geq \mathrm{SDS}+1.645) .{ }^{28} 29$

\section{Blood pressure (BP)}

$\mathrm{BP}$ was measured thrice with an appropriate size cuff sitting after a period of rest, using the Dinamap 'Compact T' Monitor (Critikon Ltd). The lowest value for systolic blood pressure (SBP) and diastolic blood pressure (DBP) were recorded. BP increases with both age and height; therefore, SDS based on these parameters were calculated. ${ }^{30}$ Established definitions were taken from the European Society for Hypertension guidelines; 'High-normal' BP was between the 90th and 95th percentile (SDS +1.280 to +1.645 and 'hypertension' $>95$ th percentile $(>\mathrm{SDS}+1.645))^{31}$

\section{Lipid profiles}

Lipid profiles were generally non-fasted and measured on the Roche Cobas 8000 modular analyser. Profiles consisted of total cholesterol (TC), low-density lipoprotein (LDL), high-density lipoprotein (HDL) and triglycerides. Recommended levels of TC, LDL, HDL and triglycerides were $<4.0,<2.6,>1.1$ and $<4.5 \mathrm{mmol} / \mathrm{L}$, respectively. ${ }^{32} 33$

\section{Covariates}

Age at diagnosis was calculated in years by subtracting date of diagnosis from date of birth. Diabetes duration was calculated in years by subtracting the clinic visit date from the diagnosis date. HbAlc was measured using the point of care Siemens/Bayer DCA 2000+ analyser. Good and poor glycemic control was defined as $<58$ and $>80 \mathrm{mmol} / \mathrm{mol}$ respectively, as per national guidelines for the study period. ${ }^{34}$ Ethnicity was defined by self-report and grouped to reflect the local ethnic mix into six broad groups: white, mixed-ethnicity, African-Somali, black-other, Bangladeshi and Asian-other (predominantly South Asian).

\section{Data analysis}

Baseline characteristics across the population were examined. Prevalence of abnormal measure and associations between the outcomes of interest and hypothesized covariates; age at diagnosis, gender, ethnicity, clinic and HbAlc were investigated using simple regression models at diagnosis and the population mean follow-up (4 years). Categorical variables were compared using $\chi^{2}$ tests. 
Longitudinal modeling analysis

The raw data for each outcome was reviewed, and the relationship with diabetes duration was found to be linear. Associations between outcomes of interest and diabetes duration were assessed using linear mixed effects modeling (growth curve analysis). All measurements for each of the outcomes over the full 10-year study period were included. Triglycerides were non-normally distributed and were $\log$ transformed before analysis. Model 1 was the unadjusted growth model using diabetes duration as the temporal metric. Subsequent models were adjusted for additional hypothesized covariates, namely: (model 2) age at diagnosis, gender, ethnicity and diabetes clinic, (model 3) additionally HbA1c, (model 4) additionally height when analysing non-SDS BP measures only. Socioeconomic score was considered, but previous studies of this cohort identified little heterogeneity in levels of deprivation within this group. ${ }^{23}$ We also tested for potential interactions between ethnicity and diabetes duration in all models but found no significant effect; we therefore report models without interactions. Triglycerides were back transformed and expressed as percentage change. Subgroup analysis on children over 12 years was undertaken for BP and lipids, as screening practices differed between diabetes clinics for these variables in relation to national guidance. ${ }^{20}$ We plotted growth curves for all outcomes at the group level (ie, ethnicity) to visualize model fit.

Stata V.14 was used for all data analysis.

\section{Ethics}

All participants were anonymized making them unidentifiable. The study is registered with the Research and Development Office, GOS Institute of Child Health, UCL (University College London) (Project number 14PP08). All appropriate permissions were obtained from the relevant pediatric diabetes clinics, Barts NHS Trust.

\section{RESULTS}

\section{Study population}

Demographic data and a summary of the clinical outcomes by covariates are displayed in table 1 .

Mean age at diagnosis was 8.5 years (range 0.6-19.4). Mean or median age at first documented screening for BMI, BP and lipids was 9.3, 9.9 and 11.1 years, respectively, although there was significant variation in documented practice between diabetes clinics $(8.8-13.3$ years, $\mathrm{p}<0.01)$. Average length of follow-up was 4.3 years $(<1-10.8)$ with typically four contacts per year (1-14/year). $44 \%$ were diagnosed during the last 4 years of the study period. Additionally $31 \%$ of children were aged 16 years or older at the time of their last contact and therefore will have transitioned to adult services, reducing the length time in which they were in included within this cohort. $48 \%$ were male and $60 \%$ were non-white, with high proportions of Bangladeshi $(8.1 \%)$ and Somali $(8.0 \%)$ children, allowing these groups to be analysed separately. Mean $\mathrm{HbAlc}$ was $93.6 \mathrm{mmol} /$ $\mathrm{mol}$ at diagnosis and $73.9 \mathrm{mmol} / \mathrm{mol}$ at 4 years, resulting in $28.8 \%$ classed as poor control at follow-up. HbA1c varied by ethnicity with all minority groups averaging higher levels compared with the white group, and significant differences noted at 4-year follow-up in the mixed ethnicity, black and Bangladeshi groups $(\mathrm{p}<0.01)$.

\section{Body mass index}

$94.7 \%$ of children had documented anthropometry measurements, taken on average three times per year (range 1-9/year). Mean BMI at diagnosis was $18.9 \mathrm{~kg} / \mathrm{m}^{2}$ (+0.6SDS) and $20.0 \mathrm{~kg} / \mathrm{m}^{2}(+0.5 \mathrm{SDS})$ at 4-year follow-up. Prevalence of unhealthy weight (BMI $>85$ th percentile) was $33.8 \%$ and $34.8 \%$ at diagnosis and follow-up. Black children had the highest mean BMI at diagnosis $\left(21.2 \mathrm{~kg} / \mathrm{m}^{2} /+1.5 \mathrm{SDS}\right)$ and 4-year follow-up $(21.8 \mathrm{~kg} /$ $\mathrm{m}^{2} /+1.1$ SDS $)(\mathrm{p}<0.01)$.

\section{Blood pressure}

$78 \%$ of children had BP documented during the study period averaging thrice yearly (range 1-8/year). There was low prevalence of systolic hypertension, but abnormal DBP was $20.5 \%$ at diagnosis, rising to $31.7 \%$ at 4-year follow-up. No significant ethnic variation was noted.

\section{Lipids}

These were measured annually (range 1-3/year). Documentation of screening commenced later than other variables resulting in $65 \%$ whom had lipids recorded over the study period. Prevalence of abnormalities in TC and LDL were high at diagnosis and 4-year follow-up; $71 \%$ of TC levels were above recommendations, and $6 \%$ of LDL measures reached treatment threshold. There was no significant difference in frequency of dyslipidemia between younger children and those aged over 12 years. Rising TC and LDL correlated with poorer glycemic control $(p<0.05)$. Bangladeshi children had the highest TC and LDL at 4-year follow-up, reaching statistical significance for TC only $(5.1 \mathrm{mmol} / \mathrm{L}$ in Bangladeshi vs $4.2 \mathrm{mmol} / \mathrm{L}$ in white CYP for TC, $\mathrm{p}<0.05$; table 1 ).

The frequency of abnormal measures for each outcome was compared before and after 12 years of age. Rates of target DBP fell from $79 \%$ to $61 \%$ in older CYP $(p<0.001)$, but no difference in prevalence was found for the other variables.

\section{Longitudinal modeling analysis}

In the fully adjusted models (model 3; age at diagnosis, gender, ethnicity, diabetes clinic and HbA1c Model 4; additionally adjusted for height for non-SDS BP), there was a positive relationship between all investigated outcomes and increasing disease duration, other than triglycerides (table 2). Model 1 (unadjusted) and model 2 (adjusted for $\mathrm{HbA1c}$ ) marginally attenuated the coefficients for some variables (online supplementary tables $1-3)$. The mean number of recordings per child included 


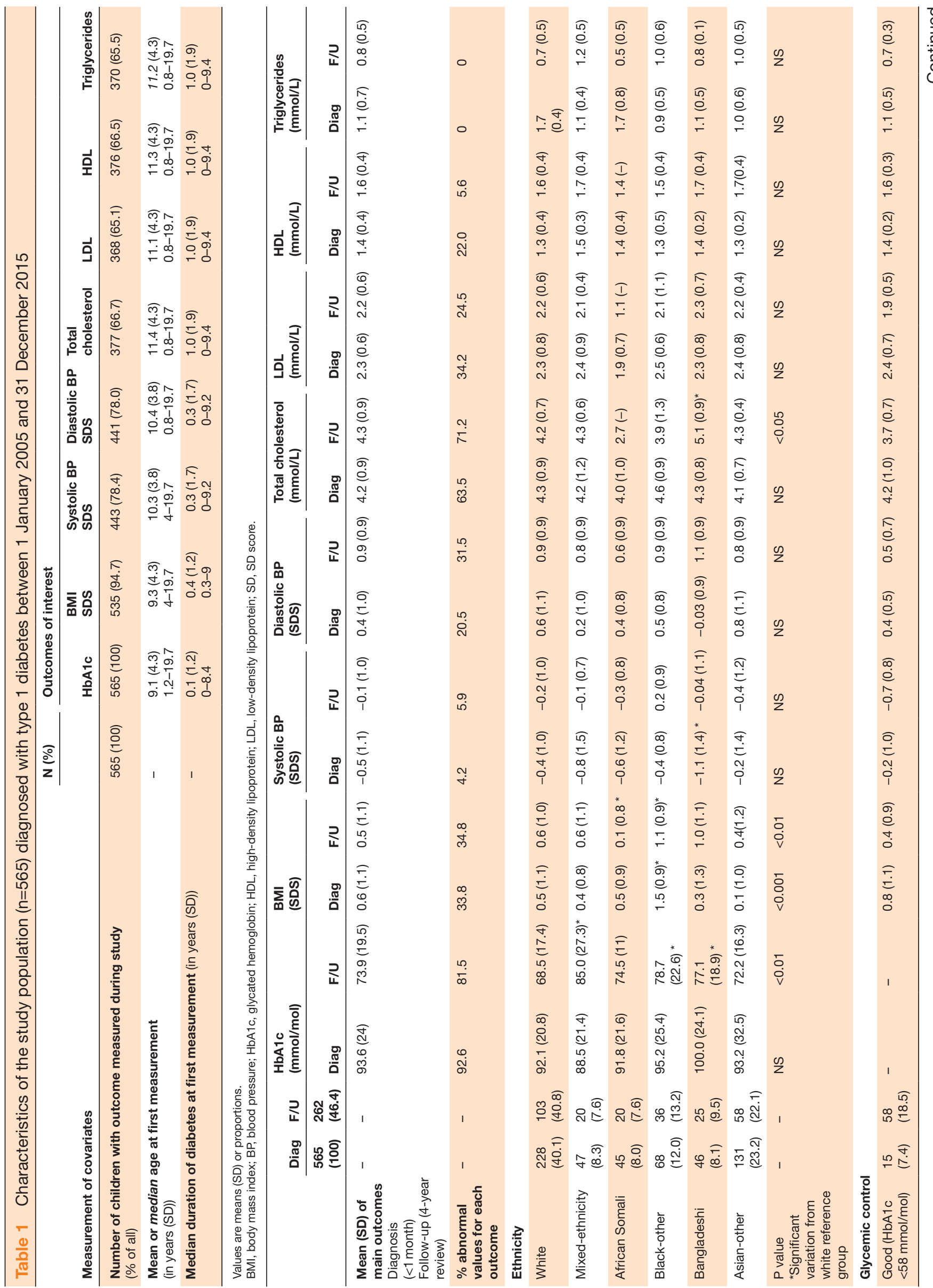


in each model were BMI 11 (range: 1-36), BP 8 (range: 1-33) and lipids: 3 (range: 2-11).

For each year of diabetes BMI increased $0.6 \mathrm{~kg} / \mathrm{m}^{2}$ (95\% CI 0.6 to 0.7 ), and BMI SDS rose annually by 0.005 $(-0.023$ to +0.045 ; table 2$)$ approximately equal to one percentile on a growth chart, although this was not statistically significant. The annual increase of BP SDS was +0.10 $(95 \%$ CI +0.08 to +0.12 ; table 2$)$ for systolic and $+0.09(95 \%$ $\mathrm{CI}+0.0$ to +0.11 ; table 2 ) for diastolic. These BP SD scores are calculated by age and height and therefore take into account the increase in BP to be expected with increasing age. A small but statistically significant rise in all of the lipid parameters other than triglycerides was also found: 0.06 (95\% CI 0.05 to 0.1 ), 0.02 (95\% CI 0.01 to 0.04 ), 0.03 (95\% CI 0.02 to 0.04$) \mathrm{mmol} / \mathrm{L} /$ year for $\mathrm{TC}, \mathrm{LDL}$ and $\mathrm{HDL}$, respectively (table 2). Rising HbAlc had a positive effect on all coefficients other than BP and triglycerides.

Significant ethnic differences were noted between outcomes and disease duration. In particular black CYP compared with white had the greatest annual increase in BMI $1.6 \mathrm{~kg} / \mathrm{m}^{2}$ (95\% CI 0.7 to 2.5 ) or $+0.6 \mathrm{SDS}$ (95\% CI $+0.3,+0.9)$, and SBP +0.3 SDS $(95 \%$ CI +0.09 to +0.5$)$ (figure 2A,B). The increase in lipids seen in the Bangladeshi compared with white CYP was also larger for both TC and LDL $0.38 \mathrm{mmol} / \mathrm{L}(95 \% \mathrm{CI} 0.10$ to 0.60$)$ and $0.30 \mathrm{mmol} / \mathrm{L} /$ year $(95 \% \mathrm{CI} 0.07$ to 0.52$)$, respectively (figure 2C,D).

Results of the subgroup analysis in CYP aged 12 years or older were based on a smaller sample of patients $(\mathrm{n}=230-296)$ and included fewer data points per child: BP 6 (1-25) and lipids 2 (1-8) (online supplementary table 4$)$. The estimates for all outcomes were similar as for the whole cohort (table 2) but only reached statistical significance for BP. However, the ethnic differences in lipid parameters were more pronounced, with annual increments in Bangladeshi children of $0.55 \mathrm{mmol} / \mathrm{L}$ (95\% CI 0.25 to 0.85 ) and $0.42 \mathrm{mmol} / \mathrm{L}$ (95\% CI 0.15 to 0.68 ) for TC and LDL, respectively.

\section{DISCUSSION}

This study was able to evaluate the prevalence of recognized CVD risk factors from diagnosis in CYP with T1D, as well as the relationship of these with both ethnicity and disease duration of up to 10 years. Prevalence of obesity and dyslipidemia was above national reported levels and were high at both diagnosis and follow-up..$^{35}$ Such abnormalities contribute to the development of atherosclerosis by increasing cardiac remodeling and endothelial dysfunction $^{36} 37$ and strongly predicts risk factors continuing into adulthood. ${ }^{38-40}$ There was no difference in prevalence of most risk factors between older or younger CYP. Screening is not advocated in children under 12 years in the UK, and NICE gives no specific management recommendations ${ }^{20}$ yet abnormalities are likely to contribute to the development of atherosclerosis below this age. ${ }^{38}$

Black and Bangladeshi CYP had the highest BMI, consistent with national obesity reports. ${ }^{29}$ Bangladeshi CYP also had the highest lipids despite not being the 


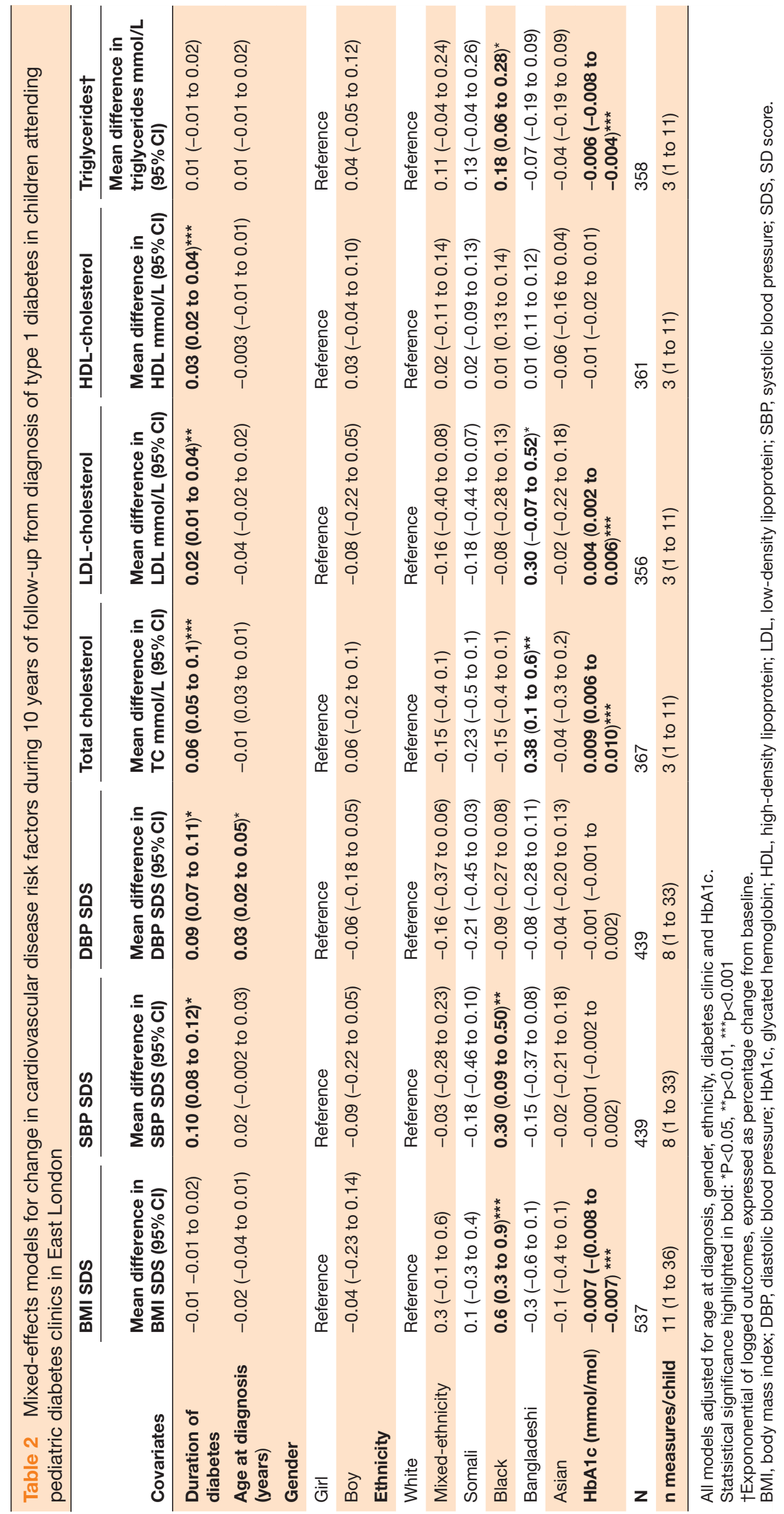

$\stackrel{m}{\longrightarrow}$ 
A

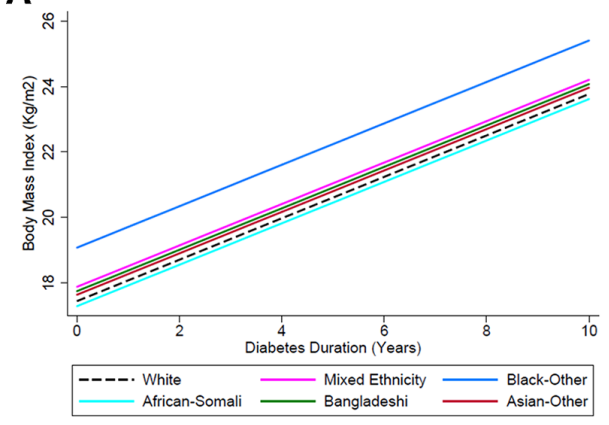

C

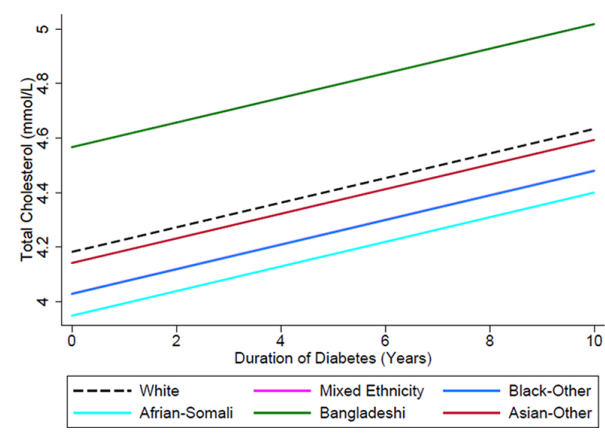

B

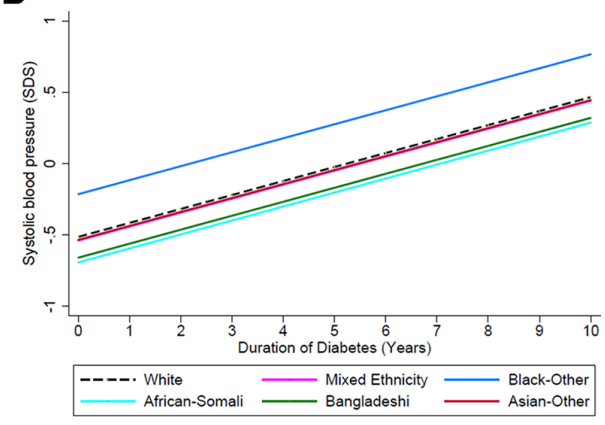

D

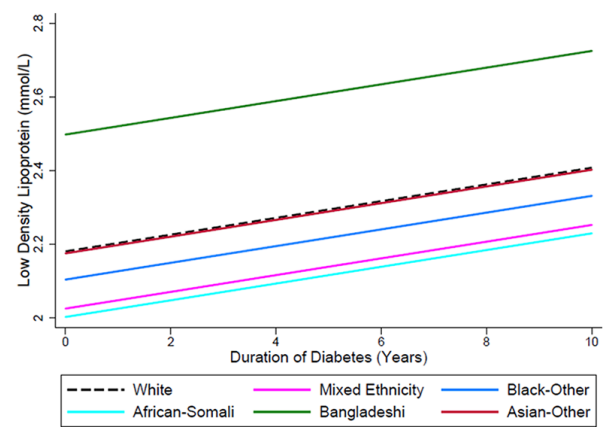

Figure 2 (A) Trajectories for change in body mass index from diagnosis by ethnicity in CYP with type 1 diabetes for fully adjusted model, demonstrating change in body mass index by ethnicity with increasing diabetes duration. (B) Growth curve for fully adjusted model, demonstrating change in systolic blood pressure SD scores by ethnicity with increasing diabetes duration. (C) Growth curve for fully adjusted model, demonstrating change in total cholesterol by ethnicity with increasing diabetes duration. (D) Growth curve for fully adjusted model, demonstrating change in low density lipoprotein by ethnicity with increasing diabetes duration. CYP, children and young people.

heaviest at follow-up. Lipid abnormalities are common in South Asian adults, particularly in Bangladeshi groups where this is independent of obesity. ${ }^{12}$ The risk of CVD in South Asians with type 2 diabetes is also increased at lower lipid levels, making any increase in lipids in this group more concerning. ${ }^{16}$

\section{Relationship with disease duration}

Almost all variables rose with cumulative disease duration, with BMI and BP having the most significant rise across the entire population. Levels of hypertension and obesity are higher in CYP with T1D compared with healthy peers. ${ }^{41}$ Black children were noted to have the highest increment for SBP, in keeping with an American cohort where African-American CYP with T1D were more likely to have hypertension at 3-year follow-up. ${ }^{42}$

There were smaller increases noted in lipids for the population as a whole in keeping with a recent large American cohort. The cumulative effect of this with ongoing diabetes is a concern. ${ }^{19}$ Furthermore, rising levels of vascular resistance in CYP with increasing diabetes duration is particularly linked to LDL levels. ${ }^{43}$ The increase in TC and LDL was most significant in the Bangladeshi group, particularly older CYP. South Asian adults have a higher atherogenic burden at any given level of LDL, making this a particular concern. ${ }^{16}$

\section{Strengths and limitations}

This study was undertaken in the largest NHS Trust in the UK and was able to include data from a large group of children attending the pediatric diabetes service over a 10-year period. Although the National Paediatric Diabetes Audit report includes the incidence of CVD risk factors annually, ${ }^{35}$ the data collection in our study allowed for the inclusion of multiple longitudinal measurements meaning prevalence from diagnosis and small incremental changes in risk factors could be identified. Individuals with a varying number of data points were able to be included, as longitudinal growth curve analysis is ideal for use in an open cohort such as this. Similar examinations of CVD risk factors in American cohorts have been reported, but to our knowledge no such UK groups has yet been described. ${ }^{19} 42$ Our cohort included a large proportion of non-white subjects that enabled us to study ethnic differences in CVD risk factors with adequate power. An earlier study exploring ethnic differences in CVD risk factors in America used broader ethnic groups that are less relevant to the UK population. ${ }^{42}$ Additionally, we were able to break down wider ethnic categories to examine the Bangladeshi and Somali groups, which have not been studied separately before. By analysing these independently, we identified the unfavourable lipid changes within the Bangladeshi group that would otherwise have been lost. 
When analysing outcomes at 4-year follow-up, data were available for $46 \%$ of CYP. This was primarily due to the open nature of our cohort meaning the maximum length of routine follow-up varied between individuals, although other reasons for CYP leaving the service cannot be excluded. The ethnic composition of the cohort remained fairly stable throughout follow-up. Measures were included for all age groups. The majority of $\mathrm{BP}$ and lipid measurements in children below the age at which NICE states screening must be commenced were recorded by one diabetes unit, where this was routine practice. However, this may not offer a full representation in this age group. ${ }^{20}$ There was no significant difference noted in levels of dyslipidemia between older and younger CYP. Diabetes antibodies were not universally tested; therefore, it is possible that some of our cohort may be misdiagnosed as T1D. We also acknowledge that our cohort is not nationally representative and so care should be taken when interpreting these results in the context of other diabetes centres. Subgroup analysis of children over 12 years lacked power in variables that were measured annually despite the large cohort. No corrections for multiple significance testing were made as in the context of multiple different hypotheses regarding different CVD risk factors and their trajectories over time these are rarely appropriate. ${ }^{44}$

This study has not been able to explore all recognized modifiable CVD risk factors. ${ }^{175}$ Albuminuria is an independent predictor of adult CVD morbidity, and rising albumin-creatinine ratios remaining within the normal range increase arterial stiffening in adolescents with T1D. ${ }^{46}{ }^{47}$ However, due to lack of reliability of this variable in the database, it was not possible to include this in our analysis. No comparison group was available for our cohort to confirm causality. However, a recent Scandinavian cohort of healthy CYP found concentrations of TC and LDL were highest in younger children compared with adolescents, suggesting the annual increments of these variables noted within our group is not reflective of age related variation. ${ }^{48}$ No information was available regarding any intervention received for abnormalities in any CVD risk factors identified, although previous studies suggest they likely remained untreated. ${ }^{9}$

\section{Implications for the future}

Our observations indicate a more focused approach to CVD prevention is required, including for those aged under 12 years. This would include prioritizing advice for a healthier approach to nutrition and exercise in addition to discussions about glycemic control. The ADA (American Diabetes Association) position statement clearly advises on undertaking detailed dietary modification and increased exercise, particularly in the presence of abnormal CVD risk factors. ${ }^{45}$ It also recommends earlier and more frequent monitoring than the UK and consideration that for certain risk factors rising levels that remain within the normal range are associated with increased future risk. High prevalence of CVD risk factors in CYP at diagnosis of T1D and further increases with cumulative diabetes duration leads one to question whether earlier intervention with medical therapies could reduce CVD events. Although use of statins in CYP is safe, they are not approved for children aged under 10 years, and the AdDIT team did not identify any reduction in the progression of atherosclerosis over 2-4 years of administration. ${ }^{49}{ }^{50}$ Perhaps the benefits for the whole population are too small to be seen over this time period, but in those in whom the rise in lipids and CVD risk is higher, such as Bangladeshi CYP, earlier intervention than the current recommendations may have a measurable effect. Clustering of CVD risk factors is common with T1D and increases the likelihood of these tracking into adulthood, compounding the risk of developing atherosclerosis. ${ }^{383945}$ Future studies focusing on whether clustering of risk factors also varies between ethnic groups may further inform individual risk predictions and thresholds for intervention between ethnicities.

\section{CONCLUSIONS}

There was high prevalence of abnormal modifiable CVD risk factors from diagnosis in this population of CYP with T1D, including children younger than current UK screening recommendations, questioning whether this age guidance should be reviewed. Increasing diabetes duration and poor glycemic control were associated with rising levels of most risk factors, particularly in Bangladeshi and black ethnic groups. Further clinical trials are needed to determine whether aggressive treatment of risk factor, such as increased monitoring or earlier pharmacological management in ethnic minority groups particularly at high risk of developing CVD is warranted. Any intervention leading to the improvement in these risk factors during early childhood has the potential for the highest impact on reducing future CVD events.

Acknowledgements We would like to acknowledge the diabetes teams of Barts Health National Health Service Trust and especially Dr Claire Hughes (Royal London Hospital), Dr Abdul Moodambail (Newham University Hospital) and Dr Paramita Cifelli (Whipps Cross Hospital) for approving the study and facilitating access to data.

Contributors SJ and RA conceived the research question. SJ and AK researched the data. SJ wrote the manuscript with contributions from RA and AK and EFG and TS.

Funding ARK is funded by the Children's Policy Research Unit at GOS Institute of Child Health.

Competing interests None declared.

Patient consent for publication Not required.

Provenance and peer review Not commissioned; externally peer reviewed.

Data availability statement All data relevant to the study are included in the article or uploaded as supplementary information.

Open access This is an open access article distributed in accordance with the Creative Commons Attribution Non Commercial (CC BY-NC 4.0) license, which permits others to distribute, remix, adapt, build upon this work non-commercially, and license their derivative works on different terms, provided the original work is properly cited, appropriate credit is given, any changes made indicated, and the use is non-commercial. See: http://creativecommons.org/licenses/by-nc/4.0/.

ORCID iD

Stephanie Jones http://orcid.org/0000-0003-4697-3169 


\section{REFERENCES}

1 Livingstone SJ, Levin D, Looker HC, et al. Estimated life expectancy in a Scottish cohort with type 1 diabetes, 2008-2010. JAMA 2015;313:37-44.

2 Dawson SI, Willis J, Florkowski CM, et al. Cause-specific mortality in insulin-treated diabetic patients: a 20-year follow-up. Diabetes Res Clin Pract 2008;80:16-23.

3 Laing SP, Swerdlow AJ, Slater SD, et al. The British diabetic association cohort study, II: cause-specific mortality in patients with insulin-treated diabetes mellitus. Diabet Med 1999;16:466-71.

4 Maftei O, Pena AS, Sullivan T, et al. Early atherosclerosis relates to urinary albumin excretion and cardiovascular risk factors in adolescents with type 1 diabetes: Adolescent type 1 Diabetes cardio-renal Intervention Trial (AdDIT). Diabetes Care 2014;37:3069-75.

5 Hadi HAR, Carr CS, Al Suwaidi J. Endothelial dysfunction: cardiovascular risk factors, therapy, and outcome. Vasc Health Risk Manag 2005;1:183-98.

6 Heilman K, Zilmer M, Zilmer K, et al. Arterial stiffness, carotid artery intima-media thickness and plasma myeloperoxidase level in children with type 1 diabetes. Diabetes Res Clin Pract 2009;84:168-73.

7 NPDA. National paediatric diabetes audit 2016-17. , 2017: 1, 81

8 Evans-Cheung TC, Bodansky HJ, Parslow RC, et al. Early deaths from ischaemic heart disease in childhood-onset type 1 diabetes. Arch Dis Child 2018;103:981-3.

9 Schwab KO, Doerfer J, Hecker W, et al. Spectrum and prevalence of atherogenic risk factors in 27,358 children, adolescents, and young adults with type 1 diabetes: cross-sectional data from the German diabetes documentation and quality management system (DPV). Diabetes Care 2006;29:218-25.

10 Egan BM, Zhao Y, Axon RN. US trends in prevalence, awareness, treatment, and control of hypertension, 1988-2008. JAMA 2010;303:2043-50.

11 Ford ES, Li C, Pearson WS, et al. Trends in hypercholesterolemia, treatment and control among United States adults. Int J Cardiol 2010;140:226-35

12 Bhopal R, Unwin N, White M, et al. Heterogeneity of coronary heart disease risk factors in Indian, Pakistani, Bangladeshi, and European origin populations: cross sectional study. BMJ 1999;319:215-20.

13 Zaman MJS, Philipson P, Chen R, et al. South Asians and coronary disease: is there discordance between effects on incidence and prognosis? Heart 2013;99:729-36.

14 Kressin NR, Orner MB, Manze M, et al. Understanding contributors to racial disparities in blood pressure control. Circulation 2010;3:173-80.

15 Wild SH, Fischbacher C, Brock A, et al. Mortality from all causes and circulatory disease by country of birth in England and Wales 2001-2003. J Public Health 2007;29:191-8.

16 Kou S, Cao JY, Yeo S, et al. Ethnicity influences cardiovascular outcomes and complications in patients with type 2 diabetes. $J$ Diabetes Complications 2018;32:144-9.

17 Yusuf S, Hawken S, Ônpuu S, et al. Effect of potentially modifiable risk factors associated with myocardial infarction in 52 countries (the INTERHEART study): case-control study. Lancet 2004;364:937-52.

18 Bilen O, Kamal A, Virani SS. Lipoprotein abnormalities in South Asians and its association with cardiovascular disease: current state and future directions. World J Cardiol 2016;8:247-57.

19 Shah AS, Maahs DM, Stafford JM, et al. Predictors of dyslipidemia over time in youth with type 1 diabetes: for the search for diabetes in youth study. Diabetes Care 2017;40:607-13.

20 National Institute for Health and Care Excellence. Diabetes (type 1 and type 2) in children and young people: diagnosis and management. NICE guideline [NG18]. London, 2015.

21 ONS. Ethnicity and national identity in England and Wales, 2012.

22 Gill B. The English indices of deprivation 2015 statistical release, 2015. Available: http://dx.doi.org/http://www.communities.gov.uk/ publications/corporate/statistics/indices2010technicalreport

23 Khanolkar AR, Amin R, Taylor-Robinson D, et al. Ethnic differences in early glycemic control in childhood-onset type 1 diabetes. BMJ Open Diabetes Res Care 2017:5:e000423.

24 Royal College of Paediatrics and Child Health. UK-WHO Growth Charts - Fact Sheet 6. Plotting and assessing infants and toddlers up to age 4 years, 2009.

25 Royal College of Paediatrics and Child Health. Fact sheet: UK 2 - 18 years Growth Chart v8, 2015.
26 Davis NL, Bursell JDH, Evans WD, et al. Body composition in children with type 1 diabetes in the first year after diagnosis: relationship to glycaemic control and cardiovascular risk. Arch Dis Child 2012;97:312-5.

27 Barlow SE. Expert Committee recommendations regarding the prevention, assessment, and treatment of child and adolescent overweight and obesity: summary report. Pediatrics 2007;120(Suppl 4):S164-S192.

28 Cole TJ, Freeman JV, Preece MA. Body mass index reference curves for the UK, 1990. Arch Dis Child 1995;73:25-9.

29 Gatineau M, Mathrani S. Obesity and ethnicity. National Obesity Observatory: Oxford, 2011.

30 Cole TJ, Green PJ. Smoothing reference centile curves: the LMS method and penalized likelihood. Stat Med 1992;11:1305-19.

31 Lurbe E, Agabiti-Rosei E, Cruickshank JK, et al. European Society of hypertension guidelines for the management of high blood pressure in children and adolescents. J Hypertens 2016;2016:1887-920.

32 Department of Health. High cholesterol. NHS Choices, 2015. Available: http://www.nhs.uk/conditions/Cholesterol/Pages/ Introduction.aspx [Accessed 20 July 2008].

33 Donaghue KC, Wadwa RP, Dimeglio LA, et al. ISPAD clinical practice consensus guidelines 2014. microvascular and macrovascular complications in children and adolescents. Pediatr Diabetes 2014;15(Suppl 2):257-69.

34 NICE. Nice guidance CG15 type 1 diabetes in children and young people: full guideline, 2015.

35 NPDA. National paediatric diabetes audit 2014-2015, 2015.

36 Bradley TJ, Slorach C, Mahmud FH, et al. Early changes in cardiovascular structure and function in adolescents with type 1 diabetes. Cardiovasc Diabetol 2016;15:31.

37 Li S, Chen W, Srinivasan SR, et al. Childhood blood pressure as a predictor of arterial stiffness in young adults. Hypertension 2004;43:541-6.

38 Berenson GS, Srinivasan SR, Bao W, et al. Association between multiple cardiovascular risk factors and atherosclerosis in children and young adults. N Engl J Med 1998;338:1650-6.

39 Myers L, Coughlin SS, Webber LS, et al. Prediction of adult cardiovascular multifactorial risk status from childhood risk factor levels: the Bogalusa heart study. Am J Epidemiol 1995;142:918-24.

40 Bao W, Threefoot SA, Srinivasan SR, et al. Essential hypertension predicted by tracking of elevated blood pressure from childhood to adulthood: the Bogalusa heart study*. Am J Hypertens 1995;8:657-65

41 Rodriguez BL, Dabelea D, Liese AD, et al. Prevalence and correlates of elevated blood pressure in youth with diabetes mellitus: the search for diabetes in youth study. J Pediatr 2010;157:245-51.

42 Redondo MJ, Libman I, Cheng P, et al. Racial/Ethnic minority youth with recent-onset type 1 diabetes have poor prognostic factors. Diabetes Care 2018;41:1017-24.

43 Schwab KO, Doerfer J, Krebs A, et al. Early atherosclerosis in childhood type 1 diabetes: role of raised systolic blood pressure in the absence of dyslipidaemia. Eur J Pediatr 2007;166:541-8.

44 Perneger TV. What's wrong with Bonferroni adjustments. BMJ 1998;316:1236-8.

45 Chiang JL, Maahs DM, Garvey KC, et al. Type 1 diabetes in children and adolescents: a position statement by the American diabetes association. Diabetes Care 2018;41:2026-44.

46 Newman DJ, Mattock MB, Dawnay ABS, et al. Systematic review on urine albumin testing for early detection of diabetic complications. Health Technol Assess 2005;9:iii-vi, xiii-163.

47 Marcovecchio ML, Woodside J, Jones T, et al. Adolescent Type 1 Diabetes Cardio-Renal Intervention Trial (AdDIT): urinary screening and baseline biochemical and cardiovascular assessments. Diabetes Care 2014;37:805-13.

48 Ruest T, Nielsen H, Lausten-thomsen U, et al. Dyslipidemia and reference values for fasting plasma lipid concentrations in Danish / North-European white children and adolescents. BMC Pediatr 2017;1:1-11.

49 Marcovecchio ML, Chiesa ST, Bond S, et al. ACE inhibitors and statins in adolescents with type 1 diabetes. N Engl J Med $2017 \cdot 377: 1733-45$

50 Canas JA, Ross JL, Taboada MV, et al. A randomized, double blind, placebo-controlled pilot trial of the safety and efficacy of atorvastatin in children with elevated low-density lipoprotein cholesterol (LDL-C) and type 1 diabetes. Pediatr Diabetes 2015;16:79-89. 